\title{
Safety of cesarean myomectomy with huge myoma compared with uncomplicated cesarean section in Indian scenario
}

\author{
Shyam Pyari Jaiswar*, Prachi Srivastava, Apala Priyadarshini, Sujata Deo, \\ Pushplata Shankhwar
}

Department of Obstetrics and Gynaecology, King George's Medical University, Lucknow, UP, India

Received: 05 October 2015

Accepted: 23 October 2015

\section{*Correspondence:}

Shyam Pyari Jaiswar,

E-mail: spjaiswar59@gmail.com

Copyright: (C) the author(s), publisher and licensee Medip Academy. This is an open-access article distributed under the terms of the Creative Commons Attribution Non-Commercial License, which permits unrestricted non-commercial use, distribution, and reproduction in any medium, provided the original work is properly cited.

\begin{abstract}
Background: Myomectomy with cesarean section has traditionally been discouraged due to risk of intractable hemorrhage and increased post-operative morbidity. In recent years, many studies have demonstrated safety of performing myomectomy with cesarean section even for large fibroids. The aim of this study was to find out the safety and clinical outcome of cesarean myomectomy in case of large myoma to encourage routine combination of both procedures.

Methods: 15 term women undergoing cesarean myomectomy constituted the study group and were compared with control group of 15 pregnant women matched on basis of gestational age and parity without myoma or any other high risk factor. Outcomes studied were duration of surgery, change in hemoglobin from pre-operative to post-operative period, need for blood transfusion, and duration of hospital stay, post-operative complications and follow up of patients up to 6 weeks postpartum.

Results: Mean age was higher in study group than control group which could be attributed to increased incidence of fibroids with increasing age. Both the groups were comparable for pre-operative hemoglobin, post-operative hemoglobin, change in hemoglobin, neonatal outcome, post-operative complications, duration of hospital stay and follow up to 6 weeks postpartum. Duration of surgery was significantly increased in study group as compared to control group. Blood transfusion was required only in study group.

Conclusions: Myomectomy may be done with cesarean section safely even for large fibroids by expert person in tertiary care setting.
\end{abstract}

Keywords: Cesarean myomectomy, Cesarean, Change in hemoglobin, Duration of surgery

\section{INTRODUCTION}

Uterine leiomyoma is the most common benign tumour of female reproductive organ. ${ }^{1}$ According to various studies prevalence of myoma in pregnancy has been reported to be between $2-5 \%$. $^{2,3}$

Myomectomy with cesarean section has traditionally been discouraged. With the exception of small, pedunculated fibroids, most of the leading obstetrics text books advice against myomectomy during cesarean delivery due to theoretical risk of intractable hemorrhage and increased postoperative morbidity. ${ }^{4,5}$

However, uterus in postpartum phase is better adapted physiologically to control hemorrhage. As contraction and retraction of muscle fibres occur, the blood vessels are closed. Also the onset of vascular changes for clot 
formation in placental bed helps in stopping the bleeding. Hence myomectomy during cesarean section may have these advantages. Myomectomy as a separate operation during cesarean section increases the risk of hemorrhage by about $10 \%{ }^{6}$

In recent years, many studies have demonstrated safety of performing myomectomy with cesarean section in single sitting even for large fibroids. If these two procedures can be safely performed at the same time, the risk of anesthetic complications, multiple surgeries, adhesions, intra and post-operative complications, exorbitant costs of operative procedures, and hospital stay could be reduced. $^{7}$

The aim of this study was to find out the safety and clinical outcome of cesarean myomectomy in case of large myoma to encourage routine combination of both these procedures which has been discouraged for long.

\section{METHODS}

This was a retrospective case control study conducted in department of Obstetrics and Gynaecology of King George's medical university, Lucknow, India .Data was collected for a period of 5 years from 2010-2015.

The study group included 15 term pregnant women who had undergone cesarean section with myomectomy in which fibroids were diagnosed antenatally by ultrasound or preoperatively by surgeon. Control group included 15 women matched on basis of gestational age and parity not having myoma and without any other high risk factor undergoing cesarean section. Patients with antepartum hemorrhage, coagulopathy, bleeding disorders, and any co- morbid conditions were excluded from the study. After complete history, clinical examination and investigations, consent for surgery was taken in both the groups. In the study group informed consent for myomectomy was also taken and blood was arranged.

In the study group, after delivering the baby and placenta by lower segment cesarean section, bladder was pushed further down and tourniquet was applied in lower segment of the uterus obliterating uterine vessels to minimize the bleeding. Myomectomy was done using same incision as cesarean section or making an incision over myoma (in case myoma was away from uterine incision given for cesarean section) and myoma was enucleated. In case of multiple myomas, maximum were removed through a single incision. . Myomectomy was done for myomas $>3 \mathrm{~cm}$ in size. Smaller myomas were left untouched. The dead space was obliterated in multiple layers with vicryl 1-0. Hemostasis was assured after deknotting the tourniquet. The myoma removed was sent for histopathological examination. In one case myoma $(12 \times 15 \mathrm{~cm})$ was occupying the lower part of the uterus. In this case after pushing the bladder down, removal of myoma was done prior to delivery of baby.
Data obtained was analyzed using SPSS software (unpaired $\mathrm{t}$ test applied for significance). Parameters studied were age, parity, gestational age at delivery, size, location and number of fibroids, pre-operative and postoperative hemoglobin, duration of surgery, post-operative complications, duration of hospital stay and follow up of patients up to 6 weeks postpartum.

Both the groups were compared with respect to age, duration of surgery (skin incision to skin closure), change in hemoglobin from preoperative to post-operative period, fetal outcome, need for blood transfusion, and duration of hospital stay, post-operative complications and follow up of patients up to 6 weeks postpartum.

\section{RESULTS}

In this study, 15 term pregnant women undergoing cesarean section with myomectomy were compared with 15 controls not having fibroids undergoing cesarean section matched on basis of gestational age and parity.

Table 1: Comparison of outcome between study and control groups.

\begin{tabular}{|llll|}
\hline Outcome & $\begin{array}{l}\text { Study } \\
\text { group } \\
(\mathbf{n}=\mathbf{1 5})\end{array}$ & $\begin{array}{l}\text { Control } \\
\text { group } \\
(\mathbf{n}=\mathbf{1 5})\end{array}$ & P value \\
\hline $\begin{array}{l}\text { Mean pre- } \\
\text { operative } \\
\text { haemoglobin } \\
\text { (gm/dl) }\end{array}$ & $12.12 \pm 0.73$ & $11.63 \pm 0.75$ & 0.084 \\
\hline $\begin{array}{l}\text { Mean post- } \\
\text { operative } \\
\text { haemoglobin } \\
\text { (gm/dl) }\end{array}$ & $10.77 \pm 0.65$ & $10.85 \pm 0.75$ & 0.759 \\
\hline $\begin{array}{l}\text { Change in } \\
\text { haemoglobin } \\
\text { from pre- } \\
\text { operative to } \\
\text { post- } \\
\text { operative } \\
\text { period } \\
\text { (gm/dl) }\end{array}$ & $1.35 \pm 0.95$ & $0.78 \pm 0.73$ & 0.077 \\
\hline $\begin{array}{l}\text { Duration of } \\
\text { surgery } \\
\text { (minutes) }\end{array}$ & $57.33 \pm 14.62$ & $29.33 \pm 6.51$ & $<0.001^{*}$ \\
\hline
\end{tabular}

Mean age in the study group was $32.4 \pm 3.44$ years with most patients being in the age group of 31-39 years and only one patient was aged 25 years. In control group the patients were in the age group of 22-29 years with mean age of $25.6 \pm 3.2$ years. Difference in age was statistically significant ( $\mathrm{p}$ value $<0.001$ ). This observation could be attributed to increased incidence of fibroids with increasing age (Table 1).

The difference between study and control group with respect to pre-operative and post-operative haemoglobin was statistically insignificant (Table 1). 
Haemoglobin drop in study group was $1.35 \pm 0.95 \mathrm{gm} \%$ as compared to $0.78 \pm 0.73 \mathrm{gm} \%$ in control group. This difference was statistically insignificant ( $\mathrm{p}$ value $=0.077$ ) (Table 1).

Table 2: Summary of cases undergoing cesarean myomectomy.

\begin{tabular}{|c|c|c|c|c|c|c|c|c|c|c|}
\hline $\begin{array}{l}\text { Serial } \\
\text { no. }\end{array}$ & $\begin{array}{l}\text { Age } \\
\text { (in } \\
\text { years) }\end{array}$ & Parity & $\begin{array}{l}\text { Number } \\
\text { of } \\
\text { myomas }\end{array}$ & Location & $\begin{array}{l}\text { Size } \\
(\mathrm{cm})\end{array}$ & $\begin{array}{l}\text { Pre- } \\
\text { operative } \\
\text { haemoglobin } \\
(\mathrm{gm} / \mathrm{dl})\end{array}$ & $\begin{array}{l}\text { Post- } \\
\text { operative } \\
\text { haemoglobin } \\
(\mathrm{gm} / \mathrm{dl})\end{array}$ & $\begin{array}{l}\text { Duration of } \\
\text { surgery(mins) }\end{array}$ & $\begin{array}{l}\text { Hb } \\
\text { change } \\
(\mathrm{gm} / \mathrm{dl})\end{array}$ & $\begin{array}{l}\text { Units } \\
\text { Of } \\
\text { Blood } \\
\text { given }\end{array}$ \\
\hline 1 & 25 & $\mathrm{G} 2 \mathrm{P} 1+0$ & 1 & UUS & $4 \times 3$ & 11.8 & 10.8 & 45 & 1 & 0 \\
\hline 2 & 39 & $\mathrm{G} 1 \mathrm{P} 0+0$ & 2 & UUS & $\begin{array}{l}8 \times 10 \\
4 \times 5\end{array}$ & 11.5 & 11 & 60 & 0.5 & 1 \\
\hline 3 & 32 & G3P2+0 & 1 & UUS & $7 \times 8$ & 12.3 & 9.5 & 55 & 2.8 & 2 \\
\hline 4 & 33 & $\mathrm{G} 1 \mathrm{P} 0+0$ & 4 & $\begin{array}{l}\text { UUS(ant } \\
\text { wall) } \\
\text { UUS(post } \\
\text { wall) } \\
\text { Broad } \\
\text { ligament }\end{array}$ & $\begin{array}{l}15 \times 10 \\
10 \times 6 \\
12 \times 12 \\
10 \times 10\end{array}$ & 10.5 & 9.8 & 55 & 0.7 & 2 \\
\hline 5 & 31 & $\mathrm{G} 1 \mathrm{P} 0+0$ & multiple & multiple & $\begin{array}{l}\text { Largest } \\
5 \times 5\end{array}$ & 12.3 & 11.9 & 55 & 0.4 & 1 \\
\hline 6 & 32 & $\mathrm{G} 2 \mathrm{P} 1+0$ & 1 & UUS & $4 \times 3$ & 12 & 11 & 55 & 1 & 0 \\
\hline 7 & 31 & $\mathrm{G} 1 \mathrm{P} 0+0$ & 1 & $\begin{array}{l}\text { UUS } \\
\text { (subserosal) }\end{array}$ & $4 \times 3$ & 11.5 & 10.7 & 40 & 0.8 & 0 \\
\hline 8 & 29 & $\mathrm{G} 1 \mathrm{P} 0+0$ & 1 & $\begin{array}{l}\text { Broad } \\
\text { ligament }\end{array}$ & $20 \times 25$ & 13.8 & 10 & 55 & 3.8 & 2 \\
\hline 9 & 31 & $\mathrm{G} 2 \mathrm{P} 1+0$ & 2 & UUS & $\begin{array}{l}7 \times 8 \\
4 \times 5\end{array}$ & 12.3 & 11.9 & 50 & 0.4 & 1 \\
\hline 10 & 32 & $\mathrm{G} 3 \mathrm{P} 2+0$ & 3 & UUS & $\begin{array}{l}10 \times 6 \\
8 \times 10\end{array}$ & 12 & 10.9 & 55 & 1.1 & 1 \\
\hline & & & & LUS & $5 \times 6$ & & & & & \\
\hline 11 & 32 & $\mathrm{G} 2 \mathrm{P} 1+0$ & 1 & UUS & $4 \times 4$ & 11.8 & 10.8 & 50 & 1 & 0 \\
\hline 12 & 33 & $\mathrm{G} 1 \mathrm{P} 0+0$ & 2 & $\begin{array}{l}\text { LUS } \\
\text { UUS }\end{array}$ & $\begin{array}{l}5 \times 6 \\
4 \times 5\end{array}$ & 12.3 & 10.7 & 50 & 1.6 & 1 \\
\hline 13 & 35 & $\mathrm{G} 2 \mathrm{P} 1+0$ & 1 & LUS & $12 \times 15$ & 12.7 & 10.6 & 60 & 2.1 & 2 \\
\hline 14 & 34 & $\mathrm{G} 3 \mathrm{P} 2+0$ & multiple & multiple & $\begin{array}{l}\text { Largest } \\
5 \times 6\end{array}$ & 12.1 & 10.9 & 60 & 1.2 & 0 \\
\hline 15 & 38 & $\mathrm{G} 2 \mathrm{P} 1+0$ & 1 & UUS & $4 \times 5$ & 12.9 & 11.1 & 50 & 1.8 & 0 \\
\hline
\end{tabular}

For study group the mean operative time was more (57.33 $\pm 14.62 \mathrm{mins})$ as compared to control group $(29.33 \pm 6.51$ mins). This difference was statistically significant ( $\mathrm{p}$ value $<0.001$ ) (Table 1$)$.

Out of 15 patients in study group, 6 patients did not require any blood transfusion, 5 patients required 1 unit of blood transfusion and 4 patients required 2 units of blood transfusion. Blood transfusion was required in patients who had significantly large fibroids $(>7 \mathrm{~cm})$ or multiple fibroids (Table 2). None of the patients in control group required blood transfusion.

There was no difference in fetal outcome, postoperative complications and duration of hospital stay in either group. Patients in both the groups were followed up to 6 weeks postpartum. No complications were noted in either group during this period.

\section{DISCUSSION}

In recent decades, some studies have demonstrated that cesarean myomectomy did not increase risk of intraoperative hemorrhage, and uterine atony compared to cesarean section without myomectomy. ${ }^{8}$

This study included 15 term pregnant women with fibroid who had undergone cesarean myomectomy and compared them with control group including 15 pregnant women without fibroid and any other high risk factor matched on basis of gestational age and parity undergoing cesarean section. The outcomes compared were operative time, change in haemoglobin level from pre-operative to postoperative period, post-operative complications, and duration of hospital stay and follow up of patients up to 6 weeks postpartum. 
Both the study and control group were comparable with respect to gestational age, parity, preoperative and postoperative haemoglobin.

The change in haemoglobin level from preoperative to post-operative period was $1.35 \pm 0.95 \mathrm{gm} \%$ in study group as compared to $0.78 \pm 0.73 \mathrm{gm} \%$ in control group. This difference was statistically insignificant ( $p$ value $=0.077$. Most of the studies in literature show that patients having fibroid undergoing cesarean myomectomy were compared with control group of patients having fibroid but undergoing cesarean section alone. Study was done by Topcu $\mathrm{HO}$ et al in which outcome of cesarean myomectomy done in 76 patients was compared with control group of 60 patients having fibroid during pregnancy but undergoing cesarean section alone. Kwawukume included 24 patients in his study to compare the efficacy and safety of myomectomy done at cesarean section with application of tourniquet compared with cesarean section without myomectomy. ${ }^{10}$ Retrospective cohort study conducted by Ashley $\mathrm{S}$ Roman et al included 111 women who underwent myomectomy at time of cesarean section and 257 women with documented fibroids during index pregnancy who underwent cesarean section alone. ${ }^{11}$ Song D conducted a meta-analysis including nine studies with 1082 women with leiomyomas. Amongst these 443 (41\%) women underwent cesarean myomectomy and 639 (59.1\%) underwent cesarean delivery alone. ${ }^{12}$ All of them found no significant difference in change in haemoglobin levels from pre-operative to post-operative period. In study conducted by Hassiakos D et al comparing 47 pregnant women having fibroids undergoing cesarean myomectomy with 94 pregnant women having myoma undergoing cesarean delivery alone, the difference between preoperative and post-operative haemoglobin was significant $(p$ value $=0.001)$ but did not differ between isolated cesarean and cesarean myomectomy combined groups. ${ }^{13}$

In the present study 6 patients did not require any blood transfusion, 5 patients required 1 unit of blood transfusion while 4 patients with significantly large volume of fibroids required 2 units of blood transfusion. None of the patients in control group required blood transfusion. Topcu et al transfused blood in both the groups but observed no significant difference in requirement of blood transfusion between both the groups. ${ }^{9}$ The study by Roman and Tabsh showed that $0.9 \%$ patients in study group required blood transfusion because of symptomatic anaemia and $1.2 \%$ patients in control group required blood transfusion. ${ }^{11}$ In study by Hassiakos et al, none of the patients required blood transfusion. $^{13}$

The duration of surgery in study group in present study was $57.33 \pm 14.62$ mins compared to $29.33 \pm 6.51 \mathrm{mins}$ in control group. This difference was statistically significant ( $p$ value<0.001) Topcu et al, Kwawukume and Hassiakos et al showed significant difference in duration of operation between the two groups in their study. $9,10,13$ Roman and Tabsh reported no significant difference in duration of surgery between study and control groups. ${ }^{11}$ Meta-analysis conducted by Song D showed operative time to be 4.94 mins longer in cesarean myomectomy group , but again the difference was not significant. ${ }^{12}$

There was no difference in duration of hospital stay and postoperative complications in present study as well as in other studies. ${ }^{9-13}$

Present study and most other studies in literature show that the only significant difference between study and control group was duration of surgery which was significantly more in study group. However, given the fact that there was no detrimental factor other than increase in duration of surgery, it would be advisable to perform myomectomy during cesarean section rather than subjecting the patient to two different surgeries.

Most of the studies included pregnant patients with myoma undergoing cesarean section alone as control group and compared them with cesarean myomectomy as study group. However, in present study term uncomplicated pregnant women not having fibroid undergoing cesarean section were taken as controls and compared with term pregnant women with fibroid undergoing cesarean myomectomy which was found safe in skilled hands at tertiary care centre with availability of blood.

\section{CONCLUSIONS}

This study supports the safety of cesarean myomectomy even with huge fibroids when compared to cesarean section alone. Thus, it is recommended that old practice of avoiding myomectomy along with cesarean section could be reconsidered. Large multicentric trials are required to define guidelines for routine practice of cesarean myomectomy. However, cesarean myomectomy in expert hands with good anaesthetic facilities in wellequipped tertiary care hospital with availability of blood appears to be a safe procedure.

Funding: No funding sources

Conflict of interest: None declared

Ethical approval: Not required

\section{REFERENCES}

1. Lippman SA, Warner M, Samuel S, Olive D, Vercillini P, Eskenazi B. Uterine fibroids and gynaecologic pain symptoms in population- based study. Fertil Steril. 2003;80(6):1488-94.

2. Liu WM, Wang PH, Tang WL, Wang IT, Tzeng CR. Uterine artery ligation for treatment of pregnant women with uterine leiomyomas who are undergoing cesarean section. Fertil Steril. 2006;86:423-8.

3. Vergani P, Locatelli A, Ghidini A, Andreani M, Sala F, Pezzullo JC . Large uterine leiomyomata and risk 
of cesarean delivery.Obstet Gyaecol Clin. 2007;33:153-69

4. Depp R. Caesarean delivery. In: Obstetrics: normal and problem pregnancies. Edited by: Gabbe SG, Niebyl JR, Simpson JL. New York: Churchill Livingstone. 2002:599.

5. Cunningham FG, Levenovo KJ, Bloom SL, Hauth CJ, Gilstrap LC, Hauth JC, et al. Abnormalities of the reproductive tract. In: Williams Obstetrics $23^{\text {rd }}$ edition. New York McGraw Hill. 2010:890.

6. Kant A, Manya S, Pandey R. Cesarean myomectomy. J Obstet Gynecol India. 2007;57(2):128-30.

7. Awoleke JO. Myomectomy during Caesarean Birth in Fibroid-Endemic, Low-Resource Settings Obstetrics and Gynecology International, 2013.

8. Kwon DH, Song JE, Yoon KR, Lee YK. The safety of cesarean myomectomy in women with large myomas. Obstet Gynecol Sci. 2014;57(5):367-72.

9. Topcu HO, Iskender CT, Timur H , Kaymak O, Memur T, Danisman N. Outcomes after cesarean myomectomy versus cesarean alone among pregnant patients with uterine leiomyomas. Int $\mathbf{J}$ Gynecol Obstet. Int J Gynaecol Obstet. 2015;130(3):244-6.

10. Kwawukume EY. Caesarean Myomectomy. Afr J Reprod Health. 2002;6(3):38-43.

11. Roman AS, Tabsh KMA. Myomectomy at time of cesarean delivery; a retrospective cohort study. BMC Pregnancy and Child birth 2004;4:14.

12. Song D, Zhang W, Chames MC. Myomectomy during cesarean delivery. Int $\mathbf{J}$ Gynaecol Obstet. 2013;121(3):208-13.

13. Hassiakos D, Christopoulos P, Vitoratos Z, Xarchoulakou E, Vaggos G, Papadias K. Myomectomy during cesarean section: A safe procedure? Ann N Y Acad Sci. 2006;1092:408-13.

Cite this article as: Jaiswar SP, Srivastava P, Priyadarshini A, Deo S, Shankhwar P. Safety of cesarean myomectomy with huge myoma compared with uncomplicated cesarean section in Indian scenario. Int J Reprod Contracept Obstet Gynecol 2015;4:1696-9. 